\title{
Dental Arch Dimensions in a Matched Pairs Study of Hypodontia Patients and Controls
}

\author{
Bernadette Kerekes-Máthé ${ }^{1}$, Krisztina Mártha², Matthew Brook 0’Donnell ${ }^{3}$ and Alan H Brook ${ }^{4 *}$ \\ ${ }^{1}$ Department of Morphology of Teeth and Dental Arches, Faculty of Dentistry, George Emil Palade University of Medicine, \\ Pharmacy, Science and Technology of Tirgu-Mures, Romania
}

${ }^{2}$ Department of Orthodontics, Faculty of Dentistry, George Emil Palade University of Medicine, Pharmacy, Science and Technology of Tirgu-Mures, Romania

${ }^{3}$ Annenberg School of Communication, University of Pennsylvania, Philadelphia, Pennsylvania, USA

${ }^{4}$ Professor of Dentistry, School of Dentistry, University of Adelaide, Australia, Dental Institute, Barts and the London Medical Faculty, Queen Mary University of London, United Kingdom

*Corresponding author: Alan H Brook, University of Adelaide, Professor of Dentistry, School of Dentistry, University of Adelaide,

Adelaide, Australia, Dental Institute, Barts and the London Medical Faculty, Queen Mary University of London, United Kingdom

\section{ARTICLE INFO}

Received: 慧 December 18, 2021

Published: 㗀 January 18, 2022

Citation: Bernadette Kerekes-Máthé, Krisztina Mártha, Matthew Brook O’Donnell, Alan H Brook. Dental Arch Dimensions in a Matched Pairs Study of Hypodontia Patients and Controls. Biomed J Sci \& Tech Res 41(1)-2022. BJSTR. MS.ID.006556.

Keywords: Dental Arch Dimensions; Hypodontia; Image Analysis

\section{ABSTRACT}

Background: Hypodontia is a common variation in tooth number, which presents treatment challenges. It is associated with changes in tooth size and shape and this paper explores possible concurrent changes in dental arch morphology.

Design: Images of the study models of sixty patients with 1 to 5 congenitally absent permanent teeth (other than third molars) and their matched controls were analysed using a 2D image analysis method. Measurements of the dental arches were the arch circumference, arch length, intercanine width, intermolar width and the depth of the palatal vault.

Results: The hypodontia patients had significantly smaller arch circumference, arch length and intercanine width in the upper arch than controls. Greater reductions in males were seen compared to their control group, highlighting sex differences. The different locations of the congenitally missing teeth had different impacts on the dental arch parameters.

Conclusions: This study provides background for treatment planning by showing that hypodontia does influence the dimensions of the dental arches. Different parameters are affected to different degrees related to the interacting factors of arch, sex and the location of the congenitally absent teeth. These findings are compatible with the development of the dental arches as a complex system with a network of interacting factors.

\section{Introduction}

Hypodontia is a common variation of tooth number in the population. In the permanent dentition approximately $25 \%$ of individuals have 1 or more congenitally missing third molars and some $3.5 \%$ to $7 \%$ of the population have hypodontia of other permanent teeth [1-6]. The condition is more frequent in females and approximately $90 \%$ of affected patients have less than 4 permanent teeth, other than third molars, congenitally absent. The condition can present challenges requiring careful long term 
treatment planning and care involving general practice, paediatric dentistry, orthodontics and restorative dentistry. Variations in tooth size and shape are well established in patients with congenitally missing teeth and may also occur in other components of the stomatognathic system [7-9]. As part of an international collaboration investigating the aetiology and clinical implications of hypodontia, this paper explores dental arch morphology in mild or moderate hypodontia. The dental arches and the dentition are two closely related components of the stomatognathic system, which develop in anatomical proximity over an extended time period from early in utero to early adulthood. The dental arches and the dentition are both complex systems, whose development is determined by multiple interactions between genetic, epigenetic, and environmental factors [10-12]. Interactions continue as development progresses through cellular, soft tissue and mineralisation stages to the emergence of the mature phenotype [9]. Hypodontia is an outcome of these complex interactions [13].

Similarly, in addition to genetic factors, the dimensions and shape of the dental arch are influenced by the configuration of the underlying basal bone and the actions of prenatal and postnatal environmental factors [14-17]. Postnatal environmental factors that have been identified include: the intraoral and circumoral musculature [18,19], sucking habits [20], postural and breathing patterns [21] and early loss of primary teeth [22]. There have been varying results in previous studies of dental arch morphology in patients with hypodontia. Woodsworth, et al. [23] found no significant differences in hypodontia patients compared to controls, Paulino, et al. [24] found greater intercanine and intermolar distances in the permanent dentition of adolescent and young adult men than in women, while Nelson, et al. [7] and Higgins [25] report the upper arch depth and chords were significantly reduced. They found greater differences in severe hypodontia. Sex differences are present in arch dimensions [26] and the degree of change in hypodontia may vary between male and female patients. Moreover, the differences may be greater in the upper arch than the lower [27] and may be influenced by the location of the congenitally missing teeth [7]. The aim of the present study is to investigate dental arch dimensions using a well validated 2D image analysis system $[7,28,29]$ in a sample of hypodontia patients and matched controls to determine if there are any differences and, if so, how these relate to the sex of the patient, the location of the congenitally missing teeth and the upper and lower arches.

\section{Materials and Methods}

This study was approved by the Ethics Committee of the Scientific Research of the George Emil Palade University of Medicine, Pharmacy, Science and Technology of Tirgu-Mures (Approval no. 60/07.03.2018). The participants gave their written informed consent. Sixty patients with hypodontia, 40 females and 20 males, having a mean age of $15.40 \pm 2.85$ years were included. The criteria for inclusion were the congenital absence of one to five permanent teeth, excluding third molars and that the formed permanent teeth were fully erupted. Diagnosis was based on dental history, clinical examination and orthopantomograms. Exclusion criteria were the presence of any other congenital conditions, syndromes, or a history of orthodontic treatment or tooth extraction. The same number of controls with complete permanent dentitions, matched for sex, age, ethnicity and exclusion criteria were also studied. Mean age in the control group was $15.48 \pm 2.87$ years. In order to examine the possible influence of location of the congenitally missing teeth anterior (26 cases) and posterior (31 cases) hypodontia subgroups were formed. Anterior hypodontia was defined as missing upper and lower incisors and/or canines. Posterior hypodontia was defined as missing upper and lower premolars and/or molars, excluding third molars. For these subgroups age- and sex- matched controls were selected from the control group (Figure 1).

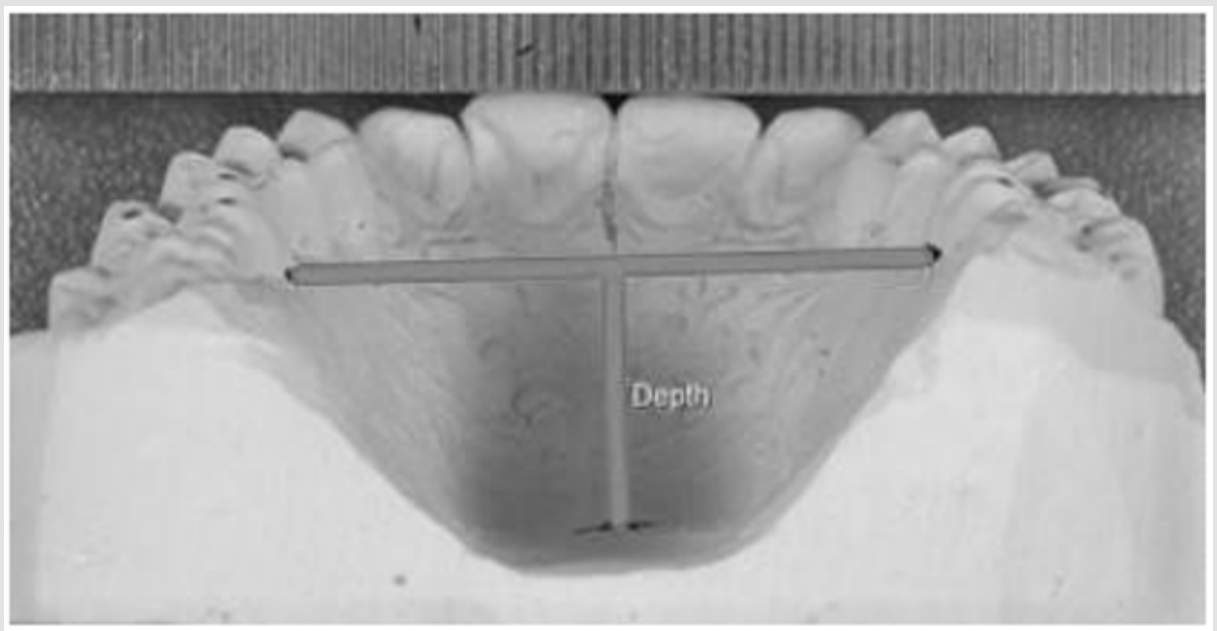

Figure 1: Image of measuring the depth of the palatal vault. 
Table 1: Definition of measured parameters.

\begin{tabular}{|c|c|}
\hline $\begin{array}{c}\text { Type of } \\
\text { measurement }\end{array}$ & Description \\
\hline Arch length & $\begin{array}{c}\text { The distance between the contact points of the } \\
\text { central incisors and the line drawn between the most } \\
\text { mesial surface points of the first molars. }\end{array}$ \\
\hline $\begin{array}{c}\text { Intercanine } \\
\text { width }\end{array}$ & Distance between the cuspal tips of the canines. \\
\hline $\begin{array}{c}\text { Intermolar } \\
\text { width }\end{array}$ & $\begin{array}{c}\text { Distance between the most buccal cervical point } \\
\text { (used as landmarks) of the first molars. }\end{array}$ \\
\hline $\begin{array}{c}\text { Arch } \\
\text { circumference }\end{array}$ & $\begin{array}{c}\text { A polyline drawn through the mesial and distal } \\
\text { contact points of teeth from the distal side of the first } \\
\text { molar on one side of the arch to the distal surface of } \\
\text { the opposite first molar. }\end{array}$ \\
\hline $\begin{array}{c}\text { Depth of the } \\
\text { palatal vault }\end{array}$ & $\begin{array}{c}\text { The deepest point of the vault was assessed visually } \\
\text { and marked with a black pen, the model was } \\
\text { positioned perpendicular on the stand and captured } \\
\text { this way. The most palatal cervical points of upper } \\
\text { first molars were connected and a perpendicular was } \\
\text { drawn on that line to the black point. }\end{array}$ \\
\hline
\end{tabular}

Alginate impressions (Ypeen Premium, SpofaDental) were taken for each individual from the upper and the lower arch. Study models were made from dental stone (FujiRock, GC). Images of the study models were taken with a digital camera (Nikon D3100, Nikon Corporation, Japan) and macro lens (Tamron SP AF-S 90 mm f/2.8). The camera was fixed above the dental cast, on an adjustable stand (Kaiser 5360, Kaiser Fototechnik, Germany) with two fixed led bulbs providing standard lighting conditions. Images of the dental arches were transferred using View NX2 (Nikon Corporation) and processed by the Image Pro Insight 9.3 software (Media Cybernetics, USA). Each image taken included a ten-millimeter scale for calibration and the measurements were made directly on the images. The 2D measurements of the dental arches were the arch circumference, arch length, intercanine width, intermolar width and the depth of the palatal vault. The definitions used for these measurements are given in (Table 1). The measurements were all carried out by the first author. Intraoperator and interoperator reproducibility was determined using the upper and lower models of 8 individuals. Three trained operators carried out the procedures separately, including image capture, calibration and measurement of selected dimensions, on 2 occasions, 2 weeks apart. Statistical analysis was performed using MedCalc (MedCalc Software Ltd). After excluding outliers, normal distribution of the data was confirmed (Shapiro-Wilk test of normality). Intraclass Correlation Coefficients (ICC) were determined to assess reproducibility of measurements. Correlations were also calculated between the number of missing teeth and the arch parameters. Significance of the differences was assessed using one-way ANOVA test, two-way ANOVA test with Bonferroni correction and Pearson's correlation coefficient. The significance level was set to 0.05 .

\section{Results}

The intra-operator and inter-operator reproducibility was excellent, with all ICC values being higher than 0.9. (Table 2).In the overall hypodontia group there were 29 patients with one congenitally absent tooth, 23 with two, 2 with three and 6 patients with four congenitally absent teeth. Lower second premolars were the most often missing teeth, followed by the upper lateral incisors, upper second premolars, lower first incisors and lower second molars. In the subgroups, for anterior hypodontia 13 female and 13 male cases were found, with upper lateral and lower central incisors missing. For posterior hypodontia 24 female and 7 male cases were found, with upper and lower second premolars and lower second molars missing. Three cases had both anterior and posterior congenitally missing teeth and were not included in either subgroup. When all hypodontia cases were compared to matched controls, significant differences were detected both in upper and lower arch parameters. Arch circumference, arch length and intercanine width values were significantly smaller in the hypodontia group for the upper arch than in controls. The more teeth that were missing, the lower the upper arch circumference was. In the lower arch intermolar width values were significantly higher in the hypodontia group than in controls (Table 3). More significant differences were seen in male patients than in female patients in the upper arch, although the interaction between the sources of variation was not significant in every case.

Table 2: Intraclass correlation coefficients.

\begin{tabular}{|l|c|c|c|c|c|}
\hline & Arch length & Intercanine width & Intermolar width & Arch circumference & Depth of the palatal vault \\
\hline For intraoperator reliability & 0.98 & 0.99 & 0.98 & 0.99 & 0.93 \\
\hline For interoperator reliability & 0.98 & 0.98 & 0.95 & 0.98 & 0.91 \\
\hline
\end{tabular}

Table 3: Mean values of measured parameters for all hypodontia patients compared with matched controls for both upper and lower arches; $\mathrm{SD}=$ Standard Deviation.

\begin{tabular}{|c|c|c|c|c|}
\hline Measured parameter & Hypodontia (mm \pm SD) (n=60) & Control (mm \pm SD) (n=60) & p value & UPPER ARCH \\
\hline \multicolumn{3}{|c|}{ UPatio } \\
\hline Arch circumference & $95.45 \pm 5.23$ & $98.63 \pm 4.81$ & $26.41 \pm 1.76$ \\
\hline Arch length & $24.95 \pm 2.60$ & 0.001 & 11.80 \\
\hline
\end{tabular}




\begin{tabular}{|c|c|c|c|c|}
\hline Intercanine width & $32.83 \pm 3.16$ & $34.82 \pm 2.04$ & $<0.001$ & 15.80 \\
\hline Intermolar width & $53.65 \pm 2.56$ & $54.21 \pm 3.13$ & 0.28 & 1.15 \\
\hline Depth of the palatal vault & $14.48 \pm 2.16$ & $14.18 \pm 2.10$ & 0.44 & 0.59 \\
\hline \multicolumn{5}{|c|}{ LOWER ARCH } \\
\hline Arch circumference & $87.91 \pm 5.46$ & $88.19 \pm 5.02$ & 0.77 & 0.08 \\
\hline Arch length & $21.00 \pm 2.25$ & $21.73 \pm 1.84$ & 0.054 & 3.76 \\
\hline Intercanine width & $26.42 \pm 1.94$ & $26.67 \pm 2.17$ & 0.50 & 0.44 \\
\hline Intermolar width & $52.71 \pm 2.26$ & $51.47 \pm 2.88$ & 0.01 & 6.82 \\
\hline
\end{tabular}

Intermolar width differences were significant in women $(p=0.02)$, while in men arch length differences $(p=0.008)$ were significant in the lower arch (Table 4). For the anterior hypodontia subgroup in the upper arch statistically significant smaller arch circumference, arch length and intercanine widths values were found in the hypodontia patients (Table 5). In the lower arch significantly greater intermolar width values were seen in the posterior hypodontia subgroup than in matched controls (Table 6). The analysis of variance highlighted differences also between the anterior and posterior case subgroups. The upper arch circumference and the upper intercanine widths was significantly lower in the anterior subgroup than in the posterior subgroup for hypodontia cases $(\mathrm{p}<0.001)$.Significant negative correlations were detected between the number of missing teeth and other parameters. All statistically significant results are shown in (Table 7). When correlating the upper arch parameters for all cases with the number of missing teeth, significant negative correlations with the intermolar width were seen. The higher the number of missing teeth, the lower the upper intermolar width was. On the other hand, when looking for correlations based on sex, strong negative correlations were detected only in men and only in the upper arch (Table 7). Regarding the anterior hypodontia subgroup, both the upper and lower arches showed significant correlations between the number of congenitally missing teeth and some of the parameters (Table 7).

Table 4: Mean values of measured parameters for females and males with hypodontia compared to matched controls; *significantly lower than values from the control group, when interpreting separately.

\begin{tabular}{|c|c|c|c|c|c|c|}
\hline \multicolumn{7}{|c|}{ UPPER ARCH } \\
\hline \multirow{2}{*}{$\begin{array}{l}\text { Measured } \\
\text { parameter }\end{array}$} & \multicolumn{2}{|c|}{ Female $(n=40)$} & \multicolumn{2}{|c|}{ Male $(n=20)$} & \multicolumn{2}{|c|}{$\begin{array}{l}\text { Interaction between sources of } \\
\text { variation (sex and case/control) }\end{array}$} \\
\hline & $\begin{array}{l}\text { Hypodontia } \\
\text { (mm } \pm \text { SD) }\end{array}$ & Control $(\mathrm{mm} \pm \mathrm{SD})$ & $\begin{array}{l}\text { Hypodontia } \\
\text { (mm } \pm \text { SD) }\end{array}$ & Control $(\mathrm{mm} \pm \mathrm{SD})$ & p value & F-ratio \\
\hline Arch circumference & $95.58 \pm 5.42$ & $97.39 \pm 3.99$ & $95.16 \pm 4.90 *$ & $101.09 \pm 5.44$ & 0.03 & 4.52 \\
\hline Arch length & $24.88 \pm 2.60^{*}$ & $26.02 \pm 1.63$ & $25.10 \pm 2.67^{*}$ & $27.24 \pm 1.80$ & 0.25 & 1.31 \\
\hline Intercanine width & $32.94 \pm 3.15^{*}$ & $34.18 \pm 1.72$ & $32.56 \pm 3.27^{*}$ & $36.17 \pm 2.02$ & 0.02 & 5.03 \\
\hline Intermolar width & $53.27 \pm 2.63$ & $53.50 \pm 2.71$ & $54.41 \pm 2.28$ & $55.63 \pm 3.48$ & 0.36 & 0.81 \\
\hline $\begin{array}{l}\text { Depth of the palatal } \\
\text { vault }\end{array}$ & $13.84 \pm 1.80$ & $13.72 \pm 0.22$ & $15.77 \pm 2.30$ & $15.11 \pm 2.86$ & 0.49 & 0.45 \\
\hline \multicolumn{7}{|c|}{ LOWER ARCH } \\
\hline \multirow{2}{*}{$\begin{array}{l}\text { Measured } \\
\text { parameter }\end{array}$} & \multicolumn{2}{|c|}{ Female $(n=40)$} & \multicolumn{2}{|c|}{ Male $(n=20)$} & \multicolumn{2}{|c|}{$\begin{array}{l}\text { Interaction between sources of } \\
\text { variation (sex and case/control) }\end{array}$} \\
\hline & $\begin{array}{l}\text { Hypodontia } \\
\text { (mm } \pm \text { SD) }\end{array}$ & Control (mm \pm SD) & $\begin{array}{l}\text { Hypodontia } \\
\text { (mm } \pm \text { SD) }\end{array}$ & Control (mm \pm SD) & $p$ value & F-ratio \\
\hline Arch circumference & $87.04 \pm 4.93$ & $86.68 \pm 4.73$ & $89.67 \pm 6.16$ & $91.21 \pm 4.25$ & 0.33 & 0.95 \\
\hline Arch length & $21.05 \pm 2.15$ & $21.22 \pm 1.76$ & $20.90 \pm 2.49^{*}$ & $22.77 \pm 1.58$ & 0.03 & 4.68 \\
\hline Intercanine width & $26.25 \pm 1.92$ & $26.19 \pm 1.98$ & $26.74 \pm 1.99$ & $27.64 \pm 2.25$ & 0.22 & 1.47 \\
\hline Intermolar width & $52.11 \pm 2.02^{* *}$ & $50.83 \pm 2.91$ & $53.91 \pm 2.27$ & $52.74 \pm 2.42$ & 0.91 & 0.01 \\
\hline
\end{tabular}

**significantly higher than values from the control group, when interpreting separately; SD=Standard Deviation. 
Table 5: Mean values of measured parameters in upper arch for anterior and posterior hypodontia subgroups and matched controls; $\dagger 3$ patients were excluded from this section as they had both anterior and posterior hypodontia; SD=Standard Deviation.

\begin{tabular}{|c|c|c|c|c|}
\hline Measured parameter & Hypodontia $(\mathrm{mm} \pm \mathrm{SD})$ & Control $(\mathrm{mm} \pm \mathrm{SD})$ & p value & F-ratio \\
\hline \multicolumn{5}{|c|}{ Anterior Hypodontia Group $(n=26) \dagger$} \\
\hline Arch circumference & $93.51 \pm 4.86$ & $99.82 \pm 5.34$ & $<0.001$ & 18.95 \\
\hline Arch length & $24.42 \pm 2.55$ & $26.74 \pm 1.88$ & 0.001 & 13.56 \\
\hline Intercanine width & $31.66 \pm 3.51$ & $35.30 \pm 2.07$ & $<0.001$ & 19.25 \\
\hline Intermolar width & $53.72 \pm 2.36$ & $55.15 \pm 3.65$ & 0.1 & 2.66 \\
\hline Depth of the palatal vault & $14.39 \pm 2.53$ & $14.74 \pm 2.56$ & 0.62 & 0.23 \\
\hline \multicolumn{5}{|c|}{ Posterior Hypodontia Group $(\mathrm{N}=31) \dagger$} \\
\hline Arch circumference & $97.09 \pm 5.21$ & $97.87 \pm 4.11$ & 0.51 & 0.43 \\
\hline Arch length & $25.34 \pm 2.71$ & $26.32 \pm 1.64$ & 0.09 & 2.97 \\
\hline Intercanine width & $34.10 \pm 2.18$ & $34.50 \pm 2.00$ & 0.47 & 0.51 \\
\hline Intermolar width & $53.86 \pm 2.68$ & $53.57 \pm 2.46$ & 0.66 & 0.19 \\
\hline Depth of the palatal vault & $14.53 \pm 1.91$ & $13.63 \pm 1.60$ & 0.05 & 4.00 \\
\hline
\end{tabular}

Table 6: Mean values of measured parameters in lower arch for anterior and posterior hypodontia subgroups and matched controls; †3 patients were excluded from this section as they had both anterior and posterior hypodontia; SD=Standard Deviation.

\begin{tabular}{|c|c|c|c|}
\hline Measured parameter & Hypodontia (mm \pm SD) & Control (mm \pm SD) & p value \\
\hline \multicolumn{4}{|c|}{ Anterior Hypodontia Group (N=26) $\dagger$} \\
\hline Arch circumference & $89.04 \pm 5.61$ & $90.04 \pm 5.32$ & 0.51 \\
\hline Arch length & $21.29 \pm 2.33$ & $22.25 \pm 1.96$ & 0.11 \\
\hline Intercanine width & $26.37 \pm 1.95$ & $27.33 \pm 2.01$ & 0.08 \\
\hline Intermolar width & $53.21 \pm 2.15$ & $52.39 \pm 2.78$ & 0.24 \\
\hline \multicolumn{2}{|c|}{ Posterior Hypodontia Group (n=31) $\dagger$} & $87.03 \pm 4.40$ & 0.83 \\
\hline Arch circumference & $87.28 \pm 5.15$ & $21.46 \pm 1.66$ & 0.14 \\
\hline Arch length & $20.74 \pm 2.12$ & $26.26 \pm 2.23$ & 0.70 \\
\hline Intercanine width & $26.46 \pm 1.92$ & $50.84 \pm 2.82$ & 0.01 \\
\hline Intermolar width & $52.43 \pm 2.21$ & \\
\hline
\end{tabular}

Table 7: Statistically significant negative correlations between the number of missing teeth and different parameters.

\begin{tabular}{|c|c|c|}
\hline \multirow{2}{*}{ Parameter } & Correlation Coefficient & \multirow{2}{*}{$p$ value } \\
\hline & (r value) & \\
\hline \multicolumn{3}{|c|}{ UPPER ARCH } \\
\hline \multicolumn{3}{|l|}{ All cases } \\
\hline Intermolar width & -0.26 & 0.04 \\
\hline \multicolumn{3}{|l|}{ Men } \\
\hline Arch circumference & -0.51 & 0.02 \\
\hline Arch length & -0.46 & 0.02 \\
\hline Intermolar width & -0.51 & 0.02 \\
\hline \multicolumn{3}{|c|}{ Anterior hypodontia cases } \\
\hline Intercanine width & -0.49 & 0.01 \\
\hline \multicolumn{3}{|c|}{ LOWER ARCH } \\
\hline \multicolumn{3}{|l|}{ All cases } \\
\hline Arch circumference & -0.51 & 0.01 \\
\hline Arch length & -0.65 & 0.002 \\
\hline \multicolumn{3}{|c|}{ Anterior hypodontia cases } \\
\hline Arch circumference & -0.42 & 0.03 \\
\hline Arch length & -0.49 & 0.01 \\
\hline Intercanine width & -0.49 & 0.01 \\
\hline
\end{tabular}


No significant correlations were found for the posterior hypodontia subgroup.

\section{Discussion}

The validity of the study can be examining the nature and structure of the sample, the study design, the pattern of hypodontia in the subjects, the measurement techniques, the reproducibility found and the raw data. The sample is derived from a single ethnic group and is of a Dental Age [30] where the dental arches have developed to maturity in width and length $[31,32]$. The sample size is satisfactory as determined by power calculations [7] and the controls are matched for age, sex, and ethnicity. The matched pairs design and the pattern of congenitally missing teeth accords with previous studies $[1,6,33]$. The accuracy and validity of the $2 \mathrm{D}$ image analysis system used here has been established over a series of studies [7,12,28,33].The hypodontia patients included in the present study had significantly smaller arch circumference, arch length and intercanine width in the upper arch than controls. This agrees with the findings of Nelson et al. [7] for their mild/moderate hypodontia group; in their severe hypodontia group the differences were greater. $\mathrm{Bu}$, et al. [26] report similar results.In the present study the only significant difference in the lower arch was a larger intermolar width in the hypodontia group. This has previously been reported by Hobkirk, et al. [34], but not by Fekonja [27] and Higgins [25]. These contrasting findings could have arisen from difference in measurement techniques.

A possible explanation for a larger lower intermolar width could be increased tongue pressure in the lower molar region arising from the position of the tongue in response to the narrower upper arch [34]. Moreover, if the lower second premolars are congenitally absent, the lower second primary molars may be retained, preventing the forward movement of the first permanent molars, and holding them back in a wider arch. Arch dimensions in females and males were investigated separately because differences had been suggested by Berwig, et al. [35]. The present study also showed sex differences, with greater reductions in males compared to their control group. In the upper arch the male hypodontia patients had highly significant reductions in arch circumference, arch length, and intercanine width, while females had less difference in these three parameters from their controls. The location of the congenitally missing teeth had significant impact on the dental arch parameters. In the upper arch, when maxillary lateral incisors were congenitally absent, the arch circumference, arch length and intercanine width were all significantly reduced, suggesting that the presence or absence of these teeth may have a substantial effect during upper arch development.

While the growth of the maxilla is affected by the missing anterior teeth, in the posterior hypodontia group, in which the maxillary second premolars were congenitally absent, no significant differences were found. In the lower arch the only significant difference was an increase in the intermolar width in the posterior hypodontia group in which the lower second premolars were absent. These changes in the dental arches occurred in those hypodontia patients most frequently encountered in clinical practice. A recent study of the orthodontic treatment of similar patients in a Western Australia private practice reported a trend away from space opening and prosthetic replacement to space closure over the years 2000 to $2017 / 18$ [36]. The findings of the present basic science study suggest that within any such general trend, different treatment plans may be appropriate for individual patients. In (Tables 3-5) while the mean values for the arch circumference, arch length and intercanine width in the maxillary arch are all smaller for hypodontia patients than those of controls, the standard deviations are greater. This indicates more variation in the amount of space available, which will also be affected by the extent of reduction in the size and shape of the teeth present. In conclusion, the evidence from this study in relation to the aim shows that hypodontia does influence the dimensions of the dental arches. Different parameters in hypodontia patients are affected to different degrees: the upper arch is more affected than the lower; males are more affected than females and the location of the congenitally absent teeth is influential.

The changes are evidence of interactions between two complex adaptive systems, the dentition and the dental arches, that are components of the stomatognathic complex. They also interact with a third component, the tongue. The underlying factors in these interactions during development are genetic, epigenetic and environmental [13]. The question remains as to the relative influence of genes and genetic mutations that are common to both the teeth and the arches compared with the environmental effects arising from the congenital absence of teeth in specific locations, resulting in a lack of stimulus to bone growth. This study provides a basis for further investigations of this and other samples to examine this question further.

\section{Acknowledgement}

This study was supported by the Internal Competition of Research Grants of George Emil Palade University of Medicine, Pharmacy, Science and Technology of Tirgu-Mures, Romania (Grant no. 15609/14/29.12.2017) and the Paul Kwok Lee Bequest Fund, University of Adelaide.

\section{References}

1. Brook AH (1984) A unifying aetiological explanation for anomalies of human tooth number and size. Arch Oral Biol 29(5): 373-378.

2. Brook AH, Winter GB (1986) Tooth Abnormalities. In: Rowe AHR, Johns RB (Eds.)., Clinical Dentistry Vol 3. Oxford: Blackwell Scientific Publications, pp. 55-103. 
3. Primozic J, Farcnik F, Ovsenik M (2012) Places in the dental arch that show a greater variability in tooth number, shape and position. Arch Oral Biol 57(6): 744-748.

4. Carter K, Worthington S (2015) Morphologic and Demographic Predictors of Third Molar Agenesis: A Systematic Review and Metaanalysis. J Dent Res 94(7): 886-894.

5. Arte S (2001) Phenotypic and Genotypic Features of Familial Hypodontia. Helsinki, Finland: Institute of Dentistry, University of Helsinki, Dissertation.

6. Khalaf K, Miskelly J, Voge E, Macfarlane TV (2014) Prevalence of hypodontia and associated factors: a systematic review and metaanalysis. J Orthod 41(4): 299-316.

7. Nelson TAB, Willmot DR, Elcock C, Smith RN, Robinson DL, et al. (2001) The use of computerised image analysis to measure the form and dimensions of the maxillary dental arches in subjects with hypodontia. In: Brook A (Edt.)., Dental Morphology. Sheffield: Sheffield Academic Press Ltd, pp. 239-246.

8. Parkin N, Elcock C, Smith RN, Griffin RC, Brook AH, et al. (2009) The aetiology of hypodontia: the prevalence, severity and location of hypodontia within families. Arch Oral Biol 54: 52 -56.

9. Brook AH, Jernvall J, Smith RN, Hughes T, Townsend GC, et al. (2014) The dentition: the outcomes of morphogenesis leading to variations of tooth number, size and shape. Aust Dent J 59(1): 131-142.

10. Brook AH, O’Donnell MB (2011) The Dentition: A Complex System Demonstrating Self-Principles. Fifth IEEE International Conference on Self-Adaptive and Self-Organizing Systems (SASO); C.P.S. Washington IEEE, pp. 208-209.

11. Hughes T, Bockmann M, Mihalilidis S, Corinna Bennett, Abbe Harris, et al. (2013) Genetic, epigenetic, and environmental influences on dentofacial structures and oral health: Ongoing studies of Australian twins and their families. Twin Research and Human Genetics 16(1): 43-51.

12. Patel D, Sassani S, Farella M, Sarbin Ranjitkar, Robin Yong, et al. (2018) Variations in dental arch morphology are outcomes of the complex adaptive system associated with the developmental variation of hypodontia. Int J Des Nat Ecodyn 13(1): 107-113.

13. Brook AH, O’Donnell MB, Hone A, Hart E, Hughes TE, et al. (2014) General and craniofacial development are complex adaptive processes influenced by diversity. Aust Dent J 59(1): 13-22.

14. Proffit WR (1986) On the aetiology of malocclusion. The Northcroft Lecture. Journal of Orthodontics 13(1): 1-11.

15. Richards LC, Townsend GC, Brown T, Burgess VB (1990) Dental arch morphology in South Australian twins. Arch Oral Biol 35(12): 983-989.

16. Townsend G, Hughes T, Luciano M, Bockmann M, Brook A, et al. (2009) Genetic and environmental influences on human dental variation. Arch Oral 54(1): 45-51.

17. Hughes T, Townsend G, Pinkerton S, MR Bockmann, WK Seow, et al (2014) The teeth and faces of twins: providing insights into dentofacial development and oral health for practising oral health professionals. Aust Dent J 59(1): 101-116.

18. Braun S, Hnat WP, Fender DE, Legan HL (1998) The form of the human dental arch. Angle Orthod 68(1): 29-36.
19. Proffit WR, Fields HW (1993) Contemporary orthodontics ( $2^{\text {nd }}$ Edn.)., St. Louis: Mosby-Year Book.

20. Warren J, Bishara SE (2002) Duration of nutritive and nonnutritive sucking behaviors and their effects on the dental arches in the primary dentition. Am J Orthod Dentofacial Orthop 121(4): 347-356.

21. Lione R, Buongiorno M, Franchi L, Cozza P (2014) Evaluation of maxillary arch dimensions and palatal morphology in mouth-breathing children by using digital dental casts. Int J Pediatr Otorhinolaryngol 78(1): 91-95.

22. Northway W, Wainright R, Demirjan A (1984) Effects of premature loss of deciduous molars. Angle Orthod 54(4): 295-329.

23. Woodworth DA, Sinclair PM, Alexander RG (1985) Bilateral congenital absence of maxillary lateral incisors: a craniofacial and dental cast analysis. Am J Orthod 87(4): 280-293.

24. Paulino V, Paredes V, Cibrian R, Gandia JL (2011) Med Oral Patol Oral Cir Bucal 16(4): e607-613

25. Higgins SA (2017) Tooth size and arch dimensions in a hypodontia patient group. Birmingham: University of Birmingham, M.Sc Thesis.

26. Bu X, Khalaf K, Hobson RS (2008) Dental arch dimensions in oligodontia patients. Am J Orthod Dentofacial Orthop 134(6): 768-772.

27. Fekonja A (2013) Comparison of mesiodistal crown dimension and arch width in subjects with and without hypodontia. J Esthet Restor Dent 25(3): 203-210.

28. Brook AH, Smith RN, Elcock C, Al Sharood M, Shah A, et al. (1998) The measurement of tooth morphology: Development and validation of a new image analysis technique. In: Dental Morphology, Proceedings of the $11^{\text {th }}$ International Symposium on Dental Morphology, Oulu University Press, pp. 380-387.

29. Brook AH, Smith RN, Elcock C (2005) The Measurement of tooth morphology: Validation of an image analysis system. In: Zadzinska $\mathrm{E}$ (Edt.)., Current Trends in Dental Morphology research, University of Lodz Press, pp. 475-482.

30. Al-Quatani SI, Hector MP, Liversidge HM (2010) Brief communication: The London Atlas of human tooth development and eruption. American Journal of Physical Anthropology 142(3): 481- 490

31. Bishara SE, Jackobsen JR, Treder J, Nowak A (1997) Arch width changes from 6 weeks to 45 years of age. Am J Orthod Dentofacial Orthop 111(4): 401-409.

32. Bishara SE, Jackobsen JR, Treder J, Nowak A (1998) Arch length changes from 6 weeks to 45 years of age. Angle Orthod 68(1): 69-74.

33. Kerekes Mathe B, Brook AH, Martha K, Szekely M, Smith RN, et al. (2015) Mild hypodontia is associated with smaller tooth dimensions and cusp numbers than in controls. Arch Oral Biol 60(9): 1442-1449.

34. Hobkirk JA, Gill DS, Jones SP (2010) Hypodontia: A team approach to management. Oxford: Wiley-Blackwell.

35. Berwig LC, Marquezan M, Milanesi J, Montenegro MM, Ardenghi TM, et al. (2018) Do gender and age influence hard palate dimensions? A systematic review. Codas 30(5): e20170216.

36. Naoum S, Allan Z, Yeap CK, J Mike Razza, Kevin Murray, et al. (2021) Trends in orthodontic management strategies for patients with congenitally missing lateral incisors and premolars. Angle Orthod 91(4): 477-483. 
ISSN: 2574-1241

DOI: 10.26717/BJSTR.2022.41.006557

Alan H Brook. Biomed J Sci \& Tech Res

(C) (P) This work is licensed under Creative

Submission Link: https://biomedres.us/submit-manuscript.php

$\begin{array}{ll}\text { BIOMEDICAL } & \text { Assets of Publishing with us } \\ \text { RESEARCHES } & \text { - Global archiving of articles } \\ \text { - Immediate, unrestricted online access }\end{array}$

